\title{
ЗАВИСИМОСТЬ ТЕПЛОВОГО СОСТОЯНИЯ ЭЛЕКТРОЦЕНТРОБЕЖНОГО НАСОСА ОТ ЧАСТОТЫ ВРАЩЕНИЯ ДВИГАТЕЛЯ
}

\author{
Сарачева Диана Азатовна',
}

sarachevadiana85@mail.ru

Вахитова Роза Ильгизовна',

roza-w@mail.ru

\author{
Уразаков Камил Рахматуллович \\ UrazakK@mail.ru \\ 1 Альметьевский государственный нефтяной институт, \\ Россия, 423450, г. Альметьевск, ул. Ленина, 2. \\ 2 Уфимский государственный нефтяной технический университет, \\ Россия, 450062, г. Уфа, ул. Космонавтов, 1.
}

\begin{abstract}
Актуальность. На нефтедобывающих промыслах РФ в настоящий момент нашли применение станции управления установок электроцентробежных насосов, которые имеют возможность изменения частоты вращения двигателя. Такие станции управления могут применяться при увеличении или снижении частоты вращения установки для оптимизации работы системы "установка электроцентробежного насоса - пласт». Учет теплового состояния установки электроцентробежного насоса имеет значение для оптимизации его эксплуатации. Применение асинхронных электродвигателей, позволяющих регулировать без перегревания погружной части частоту вращения привода, улучшает эксплуатационные показатели погружных установок. На сегодняшний день отсутствуют всесторонние теоретические исследования по применению станции управления с регулируемой частотой вращения двигателя.

Цель: исследование теплового режима погружной установки в зависимости от содержания скопившегося на приеме центробежного насоса газа.

Объект: установки электроцентробежных погружных насосов (а именно, их тепловой режим).

Результаты. Проведены исследования экспериментальных результатов эксплуатации установки электроцентробежного насоса типа ОДИ RA7-110-1500 с газосепаратором на частотах более 50 Гц. Такие промысловые исследования проводились для оценки добывающих способностей скважины. Эксперименты проводились на частотах 50, 52, 55 Гц с учетом содержания скопившегося газа в пластовой нефти на приеме центробежного насоса и его температуры. Анализ результатов проведенных экспериментов показал, что напор центробежной установки не зависит от имеющегося газосепаратора. Исследование температурного режима погружной установки проводилось с учетом содержания воды в добываемой нефти, максимального термодинамического равновесного давления пластовой жидкости, характеризующегося процессом выделения газа из нефти, содержания в нефтяном газе азота и метана и давления на входном модуле насоса. Установлено аналитическими расчетами, что к повышению температурного режима погружной установки ведет большое содержание свободного газа в межтрубном пространстве нефтяной скважины.
\end{abstract}

\section{Ключевые слова:}

Установка электроцентробежного насоса, частота вращения двигателя, станция управления, газосодержание, тепловой режим, преобразователи частоты.

\section{Введение}

В связи с интенсификацией добычи нефти в Российской Федерации активно внедряется парк погружных установок электроцентробежных насосов (УЭЦН). Для данного процесса характерно увеличение глубины спуска погружной установки, большое содержание механических примесей в пластовой нефти и скапливающегося попутного газа в межтрубном пространстве, повышение температуры добываемой нефти, интенсивное отложение солей на рабочих деталях УЭЦН [1].

Для увеличения добычи нефти применяют различные технологии. $К$ новым методам увеличения производительности установки можно отнести процесс регулирования частоты вращения электроцентробежной установки. Использование регулируемого электропривода позволяет обеспечить значительные экономические и технические до- стоинства УЭЦН [2]. Изменение частотных характеристик обеспечивает плавное и экономичное регулирование характеристики погружного электродвигателя [3]. Применение частотно-регулируемого электропривода на скважинах, оснащенных УЭЦН, дает возможность производить отбор пластовой жидкости изменением частоты вращения двигателя, сократить периодические режимы в работе скважин и, соответственно, уменьшить число отказов погружной установки, увеличить межремонтный период работы оборудования и надежность УЭЦН [4]. Также применение частотно-регулируемого электропривода облегчает ввод добывающих скважин в эксплуатацию после проведения ремонтных работ [5, 6].

Процесс изменения частоты вращения вала УЭЦН, использующийся для регулирования производительности установки, «из-за перегруза» в 
некоторых случаях может привести к аварийному выходу из строя установки. Если имеется большой объем попутного газа в добываемой пластовой жидкости, то отказы на кабельной линии могут доходить до половины всех отказов УЭЦН. Такие отказы важно анализировать. В результате проведения испытаний на прочность электрического кабеля на стендовых полигонах уменьшилось значение электрического сопротивления тока, а именно менее чем 5 МОм (критическое значение) при температуре выше $200{ }^{\circ} \mathrm{C}$. Изучение отказов, произошедших в результате перегрузки и оплавки «плоской части» электрического кабеля, демонстрирует, что эти два вида отказов одновременно часто встречаются. Статистические данные отказов указывают на зависимость температуры пластовой нефти, поступающей на входной модуль электроцентробежного насоса (ЭЦН), от места расположения погружной установки. Необходимо разбирать условия, ведущие к интенсивному процессу образования отложений, способствующих оплавке «Плоской части» погружного кабеля, и своевременно предлагать мероприятия с целью предупреждения таких отказов. Термическое состояние погружной установки в настоящее время малоизучено и не изложено в достаточном объеме в научной литературе [7, 8].

От работы станции управления (СУ) УЭЦН зависит длительность эксплуатации погружного оборудования, оптимальность работы системы «пласт-скважина-насосная установка».

Станции управления электроцентробежными насосами выполняют следующие задачи: обеспечивают требуемую защиту ЭЦН, необходимый технологический режим добывающих скважин, передачу информационных данных в телеметрические системы, хранение данных, связанных с историей работы СУ [9].

Для регулирования частоты вращения асинхронного погружного двигателя переменного тока применяются преобразователи частоты (ПЧ). ПЧ представляют собой технические устройства, которые преобразуют сетевые параметры на входе в различные частоты на выходе [10]. Современные преобразователи частоты переменного тока имеют широкий частотный диапазон [11].

Применение ПЧ дает возможность осуществить плавное регулирование производительности погружного насоса, плавный пуск и останов без превышения допустимого тока в процессе пуска, вывод после замены УЭЦН или проведения геологических и технических мероприятий на оптимальный технологический режим эксплуатации, быстродействующие максимальные защиты, достигнуть на входе , который практически близок к единице для сохранения качества электрической сети $[12,13]$.

На нефтедобывающих промыслах России в настоящее время широко используются станции управления установок ЭЦН с переменной частотой напряжения преобразователя. Такие СУ обеспечи- вают изменение частоты вращения вала погружной установки [14]. К сожалению, на сегодняшний день по использованию таких станций управления нет основательных теоретических исследований. Современные программы не учитывают процесс адаптации работы погружной УЭЦН к меняющимся режимам притока жидкости. Из анализа промысловой практики следует, что в некоторых случаях при применении станций управления с переменной частотой без проведения необходимых расчетов режимов эксплуатации скважины возможен отказ погружной установки.

\section{Исследование теплового режима} погружной установки

Для оценивания качества работы добывающей скважины по геологическим и техническим мероприятиям и изменения типоразмера УЭЦН рассмотрим результаты экспериментальной работы погружной установки на повышенных частотах.

Промысловые исследования по повышению частоты напряжения преобразователя погружной установки проводились с целью оценивания возможности увеличения добычи пластовой жидкости без дополнительных капитальных вложений. На нефтяном месторождении выделили для проведения исследований скважину, оснащенную установкой вида ОДИ RA7-110-1500, имеющую следующие параметры:

- дебит пластовой жидкости $93 \mathrm{~m}^{3} /$ сут;

- динамический (установившийся) уровень добываемой нефти 693 м;

- водосодержание $30 \%$;

- давление в нефтесборном трубопроводе 0,96 МПа;

- массовое содержание взвешенных в пластовой нести частиц $350 \mathrm{мг/л;}$

- глубина установки (подвески) погружного агрегата 2147 м;

- содержание скопившегося газа на приеме ЭЦН по результатам расчетов составило $21 \%$.

Сила электрического тока при этом соответствовала 23,9 А, а напряжение преобразователя $225 \mathrm{~B}$.

В установившемся режиме в процессе эксплуатации погружной установки с частотной характеристикой тока 52 Гц содержание на приеме центробежного насоса скопившегося газа составило $33,4 \%$. Далее приняли решение повысить частоту электрического тока до 55 Гц. При этом произвели замеры на скважине, получили следующие результаты: повысились значения дебитной характеристики добывающей скважины от 89 до $115 \mathrm{~m}^{3} /$ сут, уменьшился динамический уровень пластовой жидкости с 828 до 1236 м, а давление на устье скважины величиной в 1,0 МПа оставалось неизменным. Через 2 месяца эксплуатации этой добывающей скважины отмечалось снижение дебитной характеристики с 115 до $108 \mathrm{~m}^{3} /$ сут, а далее по истечении 1 месяца дебит еще уменьшился до $98 \mathrm{~m}^{3} /$ сут при значении установившегося (динами- 
ческого) уровня 1327 м. В дальнейшем из-за высокого значения тока произошла аварийная остановка погружной установки. При расследовании причин аварийного отказа УЭЦН на рабочих элементах насоса имелся твердый налет. Причем погружной электродвигатель не вышел из строя (не был поврежден), а погружной электрокабель, находящийся на уровне ЭЦН, был подвержен действию повышенной температуры $\left(280{ }^{\circ} \mathrm{C}\right)$. У приема газового сепаратора находился скопившийся газ в объеме $38,9 \%$. Такой режим эксплуатации для установки ОДИ RA7-110-1500 считается нормальным из-за наличия газового сепаратора в составе погружного агрегата.

При использовании погружных электрических двигателей для увеличения эффективности работы УЭЦН регулирование частоты вращения вала электроцентробежного насоса должно осуществляться без перегревания основных частей установки [15]. Изменение частоты тока в погружной установке влечет за собой изменение некоторых эксплуатационных показателей УЭЦН и частоты вращения вала ЭЦН в соответствии с имеющейся классической теорией:

$$
\frac{v_{1}}{v_{0}}=\frac{Q_{1}}{Q_{0}} ; \frac{H_{1}}{H_{0}}=\left(\frac{v_{1}}{v_{0}}\right)^{2} ; \frac{P_{1}}{P_{0}}=\left(\frac{v_{1}}{v_{0}}\right)^{3},
$$

здесь $Q_{0}, Q_{1}$ - значения дебитной характеристики до и после изменения частотной характеристики электрического тока; $H_{0}, H_{1}$ - напоры установки до и после изменения частотной характеристики электрического тока; $v_{0}, v_{1}$ - частоты тока; $P_{0}, P_{1}$ потребляемые мощности до и после изменения частоты тока.

В рассмотренных выше соотношениях (1), характерных для однородной (однофазной) пластовой продукции, в случае изменения объема скопившегося газа в нефти изменение величины коэффициента полезного действия УЭЦН не берется во внимание. Процессу выделения дополнительного объема скопившегося газа на приеме ЭЦН способствует наличие давления, снижающегося на входном модуле погружного насоса при изменении значения частоты вращения вала насоса. При этом за счет повышения величины частоты электрического тока до 55 Гц наблюдалось понижение коэффициента полезного действия УЭЦН, в том числе в скважине, которая эксплуатировалась месяц после пуска. В процессе увеличения объема свободного газа в межтрубном пространстве непосредственно на входе в электроцентробежный насос с 21 до $39 \%$ эксплуатация установки ОДИ RA7-110-1500 характеризовалась снижением величины коэффициента полезного действия погружной установки.

Проведенные расчеты показывают, что именно завышенный объем свободного газа на приеме ЭЦН способствует повышению температуры центробежного насоса. В работах А.А. Гареева рассмотрено решение вышеуказанной проблемы с учетом допущения того, что максимальное термодинами- ческое равновесное давление не зависит от такого параметра состояния, как температура [16-18]:

$$
\begin{gathered}
T w=T_{f}+\frac{q_{0} \varphi R_{2} P_{\text {нас }} P_{\text {пр }}}{2 \alpha(1-\varphi)(1-\hat{A}) h \tilde{A} P_{\text {ат }}\left(1-\frac{\delta_{\text {из }}}{R_{2}}\right)}+ \\
+\frac{q_{0} \varphi R_{2}^{2} P_{\text {нас }} P_{\text {пр }}}{2 \lambda_{\text {из }}(1-\varphi)(1-\hat{A}) h \tilde{A} P_{\text {ат }}} \ln \left(1+\frac{\delta_{\text {из }}}{R_{2}}\right),
\end{gathered}
$$

где $T_{f}$ - температура двухфазной смеси на приеме погружного насоса, ${ }^{\circ} \mathrm{K} ; \lambda_{\text {из }}-$ коэффициент теплопроводности попутного газа на корпусе ЭЦН, $\mathrm{BT} /(\mathrm{M} \cdot \mathrm{K}) ; T_{w}$ - температура в корпусе электроцентробежного насоса, ${ }^{\circ} \mathrm{K} ; \delta_{\text {из }}-$ величина газовых скоплений на поверхности ЭЦН (около 0,001 м); В обводненность скважины в долях, не более 0,98 ; $q_{0}$ - удельная мощность теплоэнергии, Вт $/ \mathrm{m}^{3} ; R_{2}-$ радиус корпусной детали ЭЦН $\left(0,005\right.$ м); $P_{\text {ат }}-$ давление окружающей среды, Мпа; $P_{\text {нас }}$ максимальное термодинамическое равновесное давление пластовой жидкости, характеризующееся процессом выделения газа из нефти, МПа; $\Gamma_{\text {ом }}$ - содержание нефтяного газа в пластовой среде, $\mathrm{M}^{3} / \mathrm{M}^{3} ; \alpha$ - коэффициент теплообмена двухфазной смеси при конвекции в рабочих элементах ЭЦН, Вт $/\left(\mathrm{m}^{2} \cdot \mathrm{K}\right) ; h-$ напорная характеристика ЭЦН с содержанием скопившегося газа в газожидкостной среде, м.

Пусть максимальное термодинамическое равновесное давление пластовой жидкости, характеризующееся процессом выделения газа из нефти, является величиной, не зависящей от температуры, а объем воды в добываемой жидкости в долях равен единице. Изменение температуры в интервале от приемной сетки входного модуля электроцентробежного насоса до максимального растворенного (дисперсного) состояния скопившегося газа во внутренней полости ЭЦН, с учетом $\ln \left(1+\frac{\delta_{\text {из }}}{R_{2}}\right)=\frac{\delta_{\text {из }}}{R_{2}}$, и упростив уравнение (2), определится по формуле:

$$
\Delta T_{w}=T_{w}-T_{f}=\frac{\varphi}{1-\varphi} \frac{q_{0} R_{2} P_{\text {нас }} P_{\text {пр }}}{2(1-B) \Gamma h P_{\text {ат }}}\left\{\frac{1}{\alpha}+\frac{\delta_{\text {из }}}{\lambda_{\text {из }}}\right\} .
$$

Зависимость (3) можно записать и в другом виде:

$$
\Delta T_{w}=T_{w}-T_{f}=\frac{q_{0} R_{2} P_{\text {нас }} P_{\text {пр }}}{2 h \Gamma P_{\text {ат }}}\left\{\frac{1}{\alpha}+\frac{\delta_{\text {из }}}{\lambda_{\text {из }}}\right\} .
$$

Обобщая результаты проведенных экспериментов, можно увидеть, что напорная характеристика погружной установки практически не зависит от наличия в составе УЭЦН газового сепаратора (значение коэффициента сепарации составляет не более $20 \%$ у газовых сепараторов различных производств $[18,19])$, а зависит от содержания в двухфазной смеси скопившегося газа на приеме ЭЦН:

$$
h=f(\varphi) .
$$

Физический смысл рассмотренного выше выражения (3) состоит в том, что на участке погружного насоса, где изменяется давление от $P_{\text {вх }}$ до $P_{\text {нас }}$, наблюдаются дополнительные выделения тепловой 
энергии при $\Delta T_{w}$. Расчет объема тепловой энергии в оставшихся участках ЭЦН, где движется однородная жидкость, определяется по известной классической зависимости [20].

Максимальное термодинамическое равновесное давление пластовой жидкости, характеризующееся процессом выделения газа из нефти, при неизменяющемся объеме нефтяного газа в пластовой жидкости (при известных значениях содержания азота и метана в добываемой нефти) можно определить с учетом температуры $P_{\text {н,t }}$ по зависимости [20]:

$$
P_{\mathrm{н}, \mathrm{t}}=P_{\mathrm{H}}+\frac{T-T_{\text {пл }}}{9,157+\frac{701,8}{\Gamma_{\text {ом }}\left(y_{\mathrm{M}}-0,8 y_{\mathrm{a}}\right)}},
$$

здесь $y_{\mathrm{a}}, y_{\text {м }}$ - соответственно объемы азота, метана в скопившемся газе в процессе разгазирования пластовой жидкости (стандартные условия) [16]; $T_{\text {пл }}$ - пластовая температура среды, ${ }^{\circ} \mathrm{K} ; \Gamma_{\text {ом }}$ - содержание нефтяного газа в пластовой среде, $\mathrm{M}^{3} / \mathrm{T} ; P_{\mathrm{H}, t}$ максимальное термодинамическое равновесное давление пластовой жидкости, характеризующееся процессом выделения газа из нефти, при температуре Т, МПа; $P_{\text {н }}$ - максимальное термодинамическое равновесное давление пластовой жидкости, характеризующееся процессом выделения газа из нефти, при пластовой температуре, МПа.

В общем случае

$$
\Gamma=\rho_{\mathrm{H}} \Gamma_{\text {ом }},
$$

где $\rho_{\text {н }}-$ плотность пластовой жидкости на приеме погружного насоса, т/ $\mathrm{M}^{3}$.

Чтобы определить зависимость температуры от величины давления насыщения в (4), учтем давление насыщения в уравнении (5). При температуре двухфазной смеси максимальное термодинамическое равновесное давление пластовой жидкости, характеризующееся процессом выделения газа из нефти, на входном модуле ЭЦН:

$$
P_{\mathrm{H}, f}=P_{\mathrm{н}}+C_{1}\left(T_{f}-T_{\text {пл }}\right),
$$

где

$$
C_{1}=\frac{1}{9,157+\frac{701,8}{\Gamma_{\text {ом }}\left(y_{\mathrm{M}}-0,8 y_{\mathrm{a}}\right)}} .
$$

Во внутренней полости ЭЦН максимальное термодинамическое равновесное давление пластовой жидкости (6), характеризующееся процессом выделения газа из нефти, при температуре $T_{w}$ в корпусе электроцентробежного насоса определится по формуле:

$$
P_{\mathrm{H}, \mathrm{w}}=P_{\mathrm{H}}+C_{1}\left(T_{w}-T_{\text {пл }}\right) .
$$

Для облегчения проведения расчетов примем постоянную $C_{2}$ :

$$
C_{2}=\frac{\varphi}{1-\varphi} \frac{q_{0} R_{2} P_{\text {пр }}}{2(1-\hat{A}) h \Gamma P_{\text {ат }}}\left\{\frac{1}{\alpha}+\frac{\delta_{\text {из }}}{\lambda_{\text {из }}}\right\} .
$$

Путем преобразования формул (3), (8), (10) получим уравнение, определяющее температуру ЭЦН с учетом содержания нефтяного газа в пластовой сре- де (7), обводненности и максимального термодинамического равновесного давления пластовой жидкости (9), характеризующегося процессом выделения газа из нефти, а также давления, установившегося у входного модуля погружной установки:

$$
\Delta T_{w}=T_{w}-T_{f}=\frac{P_{\mathrm{H}}+C_{1} \theta \Delta x}{\frac{1}{C_{2}}-C_{1}},
$$

здесь $\Delta x=L_{\mathrm{c}, \mathrm{s}}-L_{\text {нас, },}, L_{\mathrm{c}, \mathrm{B}}-$ глубина залегания кровли продуктивного пласта, м; $\theta$ - разница температур в добывающей скважине, ${ }^{\circ} \mathrm{K} / \mathrm{m} ; L_{\text {нас,в }}$ - глубина расположения погружного агрегата в вертикальной плоскости, м.

Анализ вышеприведенных выражений показывает, что необходимо выполнение неравенства:

$$
C_{1} \cdot C_{2}<1 \text {. }
$$

Из уравнения (11) видно, что для увеличения частоты вращения необходимо определить допустимую величину повышения частоты электрического тока. При учете того, что в составе попутного нефтяного газа содержание азота значительно меньше содержания метана и доля метана равна 0,8 , для упрощения преобразуем выражение (11):

$$
\begin{aligned}
& \frac{1}{C_{1}}=9,157+\frac{701,8}{\Gamma_{\text {ом }}\left(Y_{\mathrm{M}}-0,8 Y_{\mathrm{a}}\right)} \approx \\
& \approx 9,16+\frac{702}{\Gamma_{\text {ом }} Y_{\mathrm{M}}} \approx 9,16+\frac{877}{\Gamma_{\text {ом }}} .
\end{aligned}
$$

Тогда из зависимостей (12) и (13):

$$
C_{2} \leq 9,16+\frac{877}{\Gamma_{\text {ом }}}
$$

Таким образом, при повышении содержания нефтяного газа в пластовой среде сужается диапазон изменения постоянной $C_{2}(14)$, а именно его величина может уменьшаться до $C_{2} \leq 12-13$, иначе возможно критическое увеличение температуры для УЭЦН

$$
C_{2}=\frac{\varphi}{1-\varphi} \frac{q_{0} R_{2} P_{\text {пр }}}{2(1-B) h \Gamma P_{\text {ат }}}\left\{\frac{1}{\alpha}+\frac{\delta_{\text {из }}}{\lambda_{\text {из }}}\right\} .
$$

Ограничение значения постоянной $C_{2}$ ведет к ограничению группы значений: $\frac{\varphi}{1-\varphi} \frac{q_{0} R_{2} P_{\text {пр }}}{2(1-B) h \Gamma P_{\text {ат }}}$. Предположим, что по вышеуказанным данным величина $\frac{\varphi}{1-\varphi}$ (при значении скопившегося газа 0,21, установившегося на входном модуле погружного насоса) изменяется в сторону увеличения от 0,265 до 0,639 (при значении скопившегося газа 0,389 , установившегося на входном модуле центробежного насоса). Таким образом, увеличение удельной тепловой энергии $\theta_{0}$ с одновременным повышением зависимости $\frac{P_{\text {пр }}}{h(\varphi)}($ при $h(\varphi) \rightarrow 0)$, которое ограничивает в свою очередь диапазон изменения $\frac{\varphi}{1-\varphi}$, установившегося на входном модуле 
ЭЦН, происходит вследствие изменения частотной характеристики электрического тока. Поэтому необходимо учитывать, что повышенный объем газа, скопившегося на входном модуле ЭЦН, при повышении частоты вращения вала погружного насоса влечет за собой критическое повышение температуры электроцентробежного насоса.

Анализ результатов проведенных расчетов в рассмотренном случае показал, что при частоте тока 50 Гц температура ЭЦН равна $126{ }^{\circ} \mathrm{C}$, при частоте электрического тока 52 Гц $-148{ }^{\circ} \mathrm{C}$, при частоте электрического тока 55 Гц $-192{ }^{\circ} \mathrm{C}$. Таким образом, к заклиниванию погружного насоса из-за ускоренного отложения солей в рабочих органах насоса ведет повышение температуры ЭЦН до $192{ }^{\circ} \mathrm{C}$ при содержании $30 \%$ воды в нефти с содержанием нефтяного газа на приеме ЭЦН в пластовой среде.

$\mathrm{C}$ помощью расчетов показано, что повышению температуры погружного насоса способствует увеличенный объем скопившегося газа на приеме ЭЦН. Для недопущения перегрева электродвигателя УЭЦН при проектировании требуемого технологического режима скважины нужно определять тепловое состояние установки ЭЦН.

В результате анализа полученных данных промысловых исследований установлено, что в установившемся режиме эксплуатации погружной установки с частотой электрического тока 50 Гц объем скопившегося газа у входного модуля ЭЦН составил $21 \%$, с частотой электрического тока 52 Гц объем скопившегося газа у входного модуля погружного насоса - 33,4 \% , далее при повышении частоты электрического тока до 55 Гц объем скопившегося газа - 39 \%. В случае повышения частоты электрического тока наблюдается увеличение объема скопившегося газа у входного модуля ЭЦН вследствие уменьшения давления, установившегося на входе, и, следовательно, увеличение содержания и давления скопившегося газа в межтрубном пространстве.

\section{Заключение}

1. Экспериментальным образом установлено: в нефтедобывающих скважинах с установками

\section{СПИСОК ЛИТЕРАТУРЫ}

1. Шарафутдинов Р.Ф., Валиуллин Р.А., Гареев А.А. Проблема солеотложения в установках электроцентробежных насосов // Нефтяное хозяйство. - 2018. - № 9. - С. 116-121. DOI: 10.24887/0028-2448-2018-9-116-120.

2. Widell B. Saving energy through pump speed control // Design news. - 1995. - V. 50. - № 4. - P. 80

3. Yurish S.Y., Kirianaki N.V., Pallas-Areny R. Universal frequency-to-digital converter for quasy-digital and smart sensors: specifications and applications // Sensor review. - 2005. - V. 25. № 2. - P. 92-99. DOI: 10.1108/02602280510585655.

4. Мубаракшин Н.Н., Елпидинский А.А. Разработка методики расчета и планирования удельного расхода электроэнергии насосными агрегатами, оборудованными частотно-регулируемым приводом // Вестник технологического университета. 2017. - T. 20. - № 13. - С. 61-63. электроцентробежных насосов при повышении значения частоты вращения вала этого насоса в результате изменения частоты электрического тока от 50 до 55 Гц повышается объемное содержание и давление скопившегося газа в межтрубном пространстве, то есть увеличивается содержание газа, скопившегося у входного модуля погружного насоса, вследствие понижения давления на его входе. Установлена взаимосвязь между параметрами: при частоте электрического тока 50 Гц содержание нефтяного газа в пластовой среде у входного модуля погружного насоса составило $21 \%$, при частоте электрического тока 52 Гц содержание нефтяного газа в пластовой среде у входного модуля погружного насоса - 33,4 \%, при частоте электрического тока 55 Гц содержание нефтяного газа в пластовой среде у входного модуля погружного насоса - $39 \%$, также наблюдались перегрев погружного электрического двигателя и понижение коэффициента полезного действия.

2. Определен тепловой режим установки электроцентробежного насоса, учитывающий максимальное термодинамическое равновесное давление пластовой жидкости, характеризующееся процессом выделения газа из нефти, температуру пластовой среды у входного модуля погружного насоса в нефтяных скважинах с высоким содержанием нефтяного газа в пластовой жидкости. Установлено: повышению температуры электроцентробежного насоса способствует повышенное содержание нефтяного газа в пластовой среде у входного модуля погружного насоса при повышении частоты вращения насоса путем изменения частоты вращения двигателя. Температура электроцентробежного насоса соответствовала $126{ }^{\circ} \mathrm{C}$ при значении частоты вращения двигателя 50 Гц, температура электроцентробежного насоса соответствовала $148{ }^{\circ} \mathrm{C}$ при значении частоты вращения двигателя 52 Гц, и температура электроцентробежного насоса соответствовала $192{ }^{\circ} \mathrm{C}$ при значении частоты вращения двигателя 55 Гц.

5. Марьенков С.А. Обеспечение непрерывности работы частотнорегулируемого привода энергопотребителей нефтедобычи // Энергобезопасность и энергосбережение. - 2017. - № 1. C. 30-33. DOI: 10.18635/2071-2219-2017-1-30-33.

6. Лысова 0.А., Фрайштетер В.П., Смирнов А.Ю. Анализ способов пуска установок центробежных электронасосов в осложненных условиях // Известия высших учебных заведений. Горный журнал. - 2018. - № 4. - С. 87-96.

7. Вахитова Р.И., Сарачева Д.А. Роль теплового режима в установках электроцентробежных насосов // Материалы Международной научно-практической конференции, посвященной 60-летию высшего нефтегазового образования в Республике Татарстан: Достижения, проблемы и перспективы развития нефтегазовой отрасли. - Альметьевск, 2016. - С. 89-90.

8. Комплексный расчет температурного режима установки электроцентробежного насоса / С.Е. Здольник, К.Р. Уразаков, 
К.А. Бондаренко, А.В. Алфёров // Научно-технический вестник ОАО «НК Роснефть». - 2010. - № 1. - С. 36-41.

9. Alwadie A. A concise review of control techniques for reliable and efficient control of induction motor // International journal of power electronics and drive systems. - 2018. - V. 9. - № 3. P. 1124-1139. D0I: 10.11591/ijpeds.v9n3.pp1124-1139.

10. Новокрещенов 0.В., Смык В.В. Преобразователи частоты с улучшенными техническими характеристиками // Новая наука: стратегии и векторы развития. - 2017. - Т. 2. - № 3. C. $111-112$.

11. Сабра Камаль, Али Мунзер Сулейман. Особенности работы центробежных насосов с использованием преобразователя частоты вращения // Природообустройство. - 2013. - № 5. C. $64-67$.

12. Dieckmann J., Mckenney K., Brodrick J. Variable frequency drives. P. 1. The technology // Ashrae journal. - 2010. - V. 52. № 4. - P. 60-62.

13. Autonomous ac grid based on multi-infeed voltage source converter stations / G.J. Li, Y.Z. Sun, S.Y. Ruan, B.T. Ooi, S.S. Choi // Electric power components and systems. - 2010. - V. 38. № 5. - P. 558-574. DOI: 10.1080/15325000903376941.

14. Mahmoudi A., Hosseini S.A.A., Zamanian M. Non-stationary analysis of a rotating shaft with geometrical nonlinearity during passage through critical speeds // Applied mathematical modeling. - 2017. - V. 433. - P. 433-449. DOI: 10.1016/j.apm.2017.01.078.
15. Shkileva A.A., Sidorenko 0.V. Estimation of the economic effect of the use of adjustable ac electric drive at pumping stations // International journal of civil engineering and technology. -2018 . V. 9. - № 5. - P. 589-593.

16. Гареев А.А., Уразаков К.Р. Влияние коэффициента полезного действия центробежного насоса на его тепловой режим // Научно-технический журнал «Оборудование и технологии для нефтепромыслового комплекса». - 2010. - № 5. - С. 21-24.

17. Гареев А.А. 0 значении температурного режима насоса в установках электроцентробежных насосов // Научно-технический журнал «Оборудование и технологии для нефтепромыслового комплекса». - 2009. - № 1. - С. 23-29.

18. Гареев А.А. 0 предельном газосодержании на приеме электроцентробежного насоса // Научно-технический журнал «Оборудование и технологии для нефтепромыслового комплекса». 2009. - № 2. - C. 21-25.

19. Milshtein L.M. Comprehensive evaluation and selection of separators for the oil and gas industry // Chemical and petroleum engineering. - 2014. - V. 49. - № 11-12. - P. 727-735. D0I: $10.1007 / \mathrm{s} 10556-014-9826-9$.

20. Мищенко И.Т. Скважинная добыча нефти. - М.: Изд-во Федерального государственного унитарного предприятия «Нефть и газ» Российского государственного университета нефти и газа им. И.М. Губкина, 2003. - 816 с.

Поступила 12.09.2019 2.

\section{Информация об авторах}

Сарачева Д.А., кандидат технических наук, старший преподаватель кафедры электро- и теплоэнергетики Альметьевского государственного нефтяного института.

Baxumoвa P.И., кандидат технических наук, доцент кафедры электро- и теплоэнергетики Альметьевского государственного нефтяной института.

Уразаков $\boldsymbol{K} . \boldsymbol{P}$., доктор технических наук, профессор кафедры машин и оборудования нефтегазовых промыслов Уфимского государственного нефтяного технического университета. 
UDC 621.18

\title{
DEPENDENCE OF AN ELECTRIC-CENTRIFUGAL PUMP HEAT STATE ON ENGINE ROTATION FREQUENCY
}

\author{
Diana A. Saracheva', \\ sarachevadiana85@mail.ru \\ Roza I. Vakhitova', \\ roza-w@mail.ru \\ Kamil R. Urazakov \\ UrazakK@mail.ru \\ ${ }^{1}$ Almetyevsk State Oil Institute,
2, Lenin street, Almetyevsk, 423450, Russia.
${ }^{2}$ Ufa State Oil Technical University,
1, Kosmonavtov street, Ufa, 450062, Russia.
}

Relevance. Nowadays in the oil-producing fields of the Russian Federation the control stations of electric centrifugal pumps are widely used. They have the ability to change the engine speed. Such control stations can be used to increase or decrease the rotational speed of the installation to optimize the operation of the "centrifugal pump installation - formation» system. Accounting for thermal condition of the electric centrifugal pump installation is important for optimizing its operation. The use of asynchronous electric motors, which allows regulating the rotational speed of the drive without overheating the immersion part, improves the operational performance of immersion units. To date, there are no comprehensive theoretical studies on application of the control station with an adjustable frequency converter voltage.

The aim of the research is to study thermal regime of a submersible installation depending on content of gas accumulated at the centrifugal pump intake.

Object: installation of electric centrifugal submersible pumps (namely, their thermal regime).

Results. The authors have studied the experimental results of operation of an electric centrifugal pump of the type ODI RA7-110-1500 with gas separator at frequencies of more than $50 \mathrm{~Hz}$. Such field studies were carried out to assess the production capabilities of the well. The experiments were conducted at frequencies of 50,52, $55 \mathrm{~Hz}$, taking into account the content of gas accumulated in the reservoir oil at the intake of the centrifugal pump and its temperature. The analysis of the results of the experiments showed that the pressure of the centrifugal unit does not depend on the existing gas separator. Temperature mode of the submersible installation was studied taking into account water content of the reservoir oil, saturation pressure, gas factor containing gases such as nitrogen and methane, and pressure at the pump intake. It was established by analytical calculations that high content of free gas in the annular space of an oil well leads to increase in temperature mode of a submersible installation.

Key words:

Electric centrifugal pump installation, engine rotation frequency, control station, gas content, thermal mode, frequency converters.

\section{REFERENCES}

1. Sharafutdinov R.F., Valiullin R.A., Gareev A.A. The problem of scaling in installations of electric centrifugal pumps. Oil industry, 2018, no. 9, pp. 116-121. D0I: 10.24887/ 0028-2448-2018-9-116-120. In Rus.

2. Widell B. Saving energy through pump speed control. Design news, 1995, vol. 50, no. 4, pp. 80.

3. Yurish S.Y., Kirianaki N.V., Pallas-Areny R. Universal frequency-to-digital converter for quasy-digital and smart sensors: specifications and applications. Sensor review, 2005, vol. 25, no. 2, pp. 92-99. DOI: $10.1108 / 02602280510585655$.

4. Mubarakshin N.N., Elpidinsky A.A. Razrabotka metodiki rascheta i planirovaniya udelnogo raskhoda elektroenergii nasosnymi agregatami, oborudovannymi chastotno-reguliruyemym privodom [Development of methods for calculating and planning the specific energy consumption of pumping units equipped with a variable-frequency drive]. Vestnik tekhnologicheskogo universite$t a, 2017$, vol. 20, no. 13, pp. 61-63.

5. Marienkov S.A. Ensuring the continuity of the frequency-controlled drive of energy consumers of oil production. Energy Security and Energy Saving, 2017, no. 1, pp. 30-33. D0I: 10.18635 / 2071-2219-2017-1-30-33. In Rus.
6. Lysova 0.A., Freisteter V.P., Smirnov A.Yu. Analysis of starting methods for centrifugal electric pump installations in complicated conditions. News of higher educational institutions. Mountain Journal, 2018, no. 4, pp. 87-96. In Rus.

7. Vakhitova R.I., Saracheva D.A. Rol teplovogo rezhima v ustanovkakh elektrotsentrobezhnykh nasosov [Role of thermal conditions in installations of electric centrifugal pumps]. Materialy Mezhdunarodnoy nauchno-prakticheskoy konferentsii, posvyashchennoy 60-letiyu vysshego neftegazovogo obrazovaniya $v$ Respublike Tatarstan: Dostizheniya, problemy i perspektivy razvitiya neftegazovoy otrasli [Materials of the International Scientific and Practical Conference dedicated to the $60^{\text {th }}$ anniversary of higher oil and gas education in the Republic of Tatarstan: achievements, problems and prospects for the development of oil and gas industry]. Almetyevsk, 2016. pp. 89-90.

8. Zdolnik S.E., Urazakov K.R., Bondarenko K.A., Alferov A.V. Comprehensive calculation of the temperature regime of the electric centrifugal pump installation. Scientific and Technical Bulletin of Rosneft Oil Company, 2010, no. 1, pp. 36-41. In Rus.

9. Alwadie A. A concise review of control techniques for reliable and efficient control of induction motor. International journal of power electronics and drive systems, 2018, vol. 9, no. 3, pp. 1124-1139. DOI: 10.11591/ijpeds.v9n3.pp1124-1139. 
10. Novokreschenov 0.V., Smyk V.V. Preobrazovateli chastoty s uluchshennymi tekhnicheskimi kharakteristikami [Frequency converters with improved technical characteristics]. Novaya nauka: strategii i vektory razvitiya, 2017, vol. 2, no. 3, pp. 111-112.

11. Sabra Kamal, Ali Munzer Suleiman. Features of the operation of centrifugal pumps using a rotational frequency converter. Environmental management, 2013, no. 5, pp. 64-67. In Rus.

12. Dieckmann J., Mckenney K., Brodrick J. Variable frequency drives. P. 1. The technology. Ashrae journal, 2010, vol. 52, no. 4, pp. $60-62$.

13. Li G.J., Sun Y.Z., Ruan S.Y., Ooi B.T., Choi S.S. Autonomous ac grid based on multi-infeed voltage source converter stations. Electric power components and systems, 2010, vol. 38, no. 5, pp. 558-574. DOI: $10.1080 / 15325000903376941$.

14. Mahmoudi A., Hosseini S.A.A., Zamanian M. Non-stationary analysis of a rotating shaft with geometrical nonlinearity during passage through critical speeds. Applied mathematical modeling, 2017, vol. 433, pp. 433-449. DOI: 10.1016/j.apm.2017.01.078.

15. Shkileva A.A., Sidorenko 0.V. Estimation of the economic effect of the use of adjustable ac electric drive at pumping stations. International journal of civil engineering and technology, 2018, vol. 9, no. 5, pp. 589-593.

\section{Information about the authors}

Diana A. Saracheva, Cand. Sc., senior lecturer, Almetyevsk State Oil Institute.

Roza I. Vakhitova, Cand. Sc., associate professor, Almetyevsk State Oil Institute.

Kamil R. Urazakov, Dr. Sc., professor, Ufa State Oil Technical University.
16. Gareev A.A., Urazakov K.R. Influence of the efficiency of a centrifugal pump on its thermal mode. Journal Equipment and Technologies for the Oilfield Complex, 2010, no. 5, pp. 21-24. In Rus.

17. Gareev A.A. About the value of the temperature mode of the pump in the electric centrifugal pump installations. Journal Equipment and Technologies for the Oilfield Complex, 2009, no. 1, pp. 23-29. In Rus.

18. Gareev A.A. On the limiting gas content at the intake of an electric centrifugal pump. Journal Equipment and Technologies for the Oilfield Complex, 2009, no. 2, pp. 21-25. In Rus.

19. Milshtein L.M. Comprehensive evaluation and selection of separators for the oil and gas industry. Chemical and petroleum engineering, 2014, vol. 49, no. 11-12, pp. 727-735. DOI: 10.1007/s10556-014-9826-9.

20. Mishchenko I.T. Skvazhinnaya dobycha nefti [Downhole oil production]. Moscow, Oil and Gas Publ. house of the I.M. Gubkin Russian State University of Oil and Gas, 2003. 816 p.

Received: 12 September 2019. 